\title{
A caixa acústica na novela Florim: expansão de gêneros e autoria
}

\author{
The acoustic box in the novela Florim: Expansion of genres and authorship \\ La caja acústica en la telenovela Florim: expansión de géneros y autoría \\ Edma Cristina Alencar de Góis*
}

\begin{abstract}
Resumo
A novela Florim (2020), de Ruth Ducaso, dá continuidade ao projeto da escritora baiana Luciany Aparecida que, entre outras marcas, utiliza diferentes assinaturas poéticas a depender da dicção e do efeito que pretende produzir como fatura do texto. Nesta obra, condensada em menos de 70 páginas, o leitor conhece a personagem Dita, uma mulher que trabalha no tráfico de drogas, é vendedora de dendê na feira, tem "nove filho" e sonha ser nomeada poeta. Florim é conduzida por três vozes intercaladas; a voz da narradora Dita, o diário da protagonista e a poesia de Dita. Além das três marcações (narração/diário/poesia), há ainda um quarto elemento, também de destaque em todo o texto, a ser creditado à Ruth Ducaso, a voz do Prólogo. São intervenções entre parênteses, em um primeiro momento lembrando o teatro clássico, e que também evocam as "experiências corais" de que fala Flora Sussekind (2013). Neste artigo, analiso as manobras operadas pela escritora Luciany Aparecida, notadamente a assinatura poética e a expansão dos gêneros, com vistas a observar como alguns empreendimentos do contemporâneo propõem novas formas para o literário. Neles, o leitor em um gesto interessado e ativo não se baseia apenas na noção de reconhecimento, mas lança mão de um repertório performático, comum à poesia e ao teatro. Florim, portanto, apesar de catalogado como "novela", transcende o formato anunciado, como um exemplar da pós-autonomia.
\end{abstract}

Palavras-chave: experiências corais, expansão dos géneros, autoria.

\section{Abstract}

The novela Florim (2020), by Ruth Ducaso, continues the project of Bahian writer Luciany Aparecida, who, among other resources, uses different poetic signatures depending on the diction and effect that she intends to produce as the making of the text. In this work, condensed into less than seventy pages, the reader meets the character Dita, a woman who works in the drug trade, is a palm oil seller at the fair, has "nine children" and dreams of being called a poet. Florim is conducted by three interspersed voices; the voice of the narrator Dita, the protagonist's diary, and Dita's poetry. In addition to the three voices (narrative/diary/poetry), there is also a fourth element, also prominent throughout the text, to be credited to Ruth Ducaso, the voice of the Prologue. They are interventions in parentheses, at first reminiscent of classical theatre, and which also evoke the "choir experiences" mentioned by Flora Sussekind (2013). In this article, I analyse the manoeuvrers operated by the writer Luciany Aparecida, notably the signature and expansion of genres. In them, the reader in an interested and active gesture is not based only on the notion of recognition, but makes use of a performative

\section{Resumen}

La novela Florim (editora paraLeLo13S, 2020), de Ruth Ducaso, continúa el proyecto de la escritora bahiana Luciany Aparecida, que, entre otras marcas, utiliza diferentes firmas poéticas en función de la dicción y el efecto que pretende producir como la hechura del texto. En esta obra, condensada en menos de setenta páginas, el lector conoce al personaje Dita, una mujer que trabaja en el narcotráfico, vende palma aceitera en la feria, tiene "nueve hijo" y sueña con ser nombrada poeta. Florim está dirigida por tres voces intercaladas: la voz de la narradora Dita, el diario de la protagonista y la poesía de Dita. Además de las tres marcas (narrativa/diario/poesía), también hay un cuarto elemento, destacado a lo largo del texto, que se le atribuye a Ruth Ducaso: la voz del Prólogo. Son intervenciones entre paréntesis que, en un principio, recuerdan al teatro clásico y que igualmente evocan a las "experiencias corales" de las que trata Flora Sussekind (2013). En este artículo analizo las maniobras de la escritora Luciany Aparecida, en particular la firma y la expansión de géneros, con miras a observar cómo algunos empeños contemporáneos proponen nuevas formas para lo literario. En ellos, el lector, en un gesto interesado y activo, no se basa únicamente en la noción de reconocimiento, sino hace uso de un repertorio

\footnotetext{
*Universidade do Estado da Bahia (Uneb), Salvador, BA, Brasil. (Dorcid.org/0000-0001-9653-0695. E-mail: edmagois@ gmail.com
} 
repertoire, common to poetry and theatre. Florim, therefore, despite being catalogued as a "novela", transcends the advertised format, as an example of post-autonomy.

Keywords: choir experiences, expansion of genres, authorship. performativo, común a la poesía y al teatro. Florim, por tanto, a pesar de catalogarse como "telenovela", trasciende el formato anunciado como un ejemplo de posautonomía.

Palabras clave: experiencias corales, expansión de géneros, autoría.

Era final de abril de 2021, quando dois homens, Bruno Barros, 29 anos, e Yan Barros, 19, tio e sobrinho, foram encontrados mortos e com sinais de tortura dentro de um porta-malas de um carro na periferia de Salvador. Dizia-se à época que eles teriam sido entregues pelos seguranças de uma grande rede de supermercados da capital baiana a traficantes, depois de furtarem quatro pacotes com $5 \mathrm{~kg}$ de carne. A sequência do enredo é muito previsível: a rede de supermercados saiu de cena, alegando ter aberto uma sindicância interna e afastado os seguranças, e a polícia, em tese, continua investigando o caso. O extermínio recorrente da população negra e jovem de Salvador e espelho do Brasil é resultado da desestrutura social, do racismo e da convivência do Estado por meio das forças policiais. Não à toa, o tema salta da terra firme para o campo das artes, em produções que pretendem amplificar o debate e alargar os horizontes de origem do problema. A novela Florim, de Ruth Ducaso (2020), é um dos exemplos mais recentes de recuperação do contexto de dramas sociais da população negra em uma cidade fictícia muito parecida com Salvador, a Cidade Sanha.

Apesar dos elementos que mostram ser Florim uma narrativa do contemporâneo (os espaços urbanos, a realidade do tráfico de drogas das grandes cidades, por exemplo), a novela abre um tempo-espaço em que é possível percebermos a história em diferentes momentos e como se por meio dele fosse possível enxergar uma filiação histórica, antes mesmo do que literária. A personagem Dita é o contemporâneo transpassado pelo tempo e sua história esgarça o imaginário sobre a população negra ao passo que explora também os formatos do literário. Ali estético e ético servem-se um do outro em prol de uma mesma proposição - por meio de novas formas de narrar, contar outros modos de existir.

Na cosmologia Yorubá, a palavra florim refere-se a uma adaga de ponta curva que pode ser um dos símbolos da orixá Yansã. Essa espada curta nomeia a novela e sinaliza possíveis campos de significações do livro. A novela conta uma história repetida quase que diariamente, por meio da personagem Dita, uma vendedora de dendê na feira, traficante de drogas, que sonha ser nomeada poeta, mas acaba vítima da poderosa tecnologia do racismo. A narrativa acompanha a vida dessa mulher que ganha dinheiro com trabalhos precários ou com o crime, cria os filhos sozinha e, ainda assim, alimenta o sonho de que sua escrita seja reconhecida. É justamente nesse último aspecto, nesse desejo de ser chamada do que ela já é - escritora de poesia, que o livro promove um deslocamento dos sujeitos marginalizados e por muito tempo interditados ao acesso à escrita. Dita filia-se a personagens como Carolina, Macabéa e Rísia ${ }^{1}$, mulheres que também foram interditadas em suas existências.

Alguns indícios revelam que Florim espera desafiar não apenas os números estatísticos referentes à morte de pessoas negras ou os modos como esses sujeitos são tradicionalmente representados nas narrativas brasileiras. A composição formal da obra põe em questão a institucionalidade do literário. Um primeiro aspecto que corrobora essa hipótese é de que Ruth Ducaso, quem assina a obra, assim como Dita, também é uma invenção. Trata-se de uma das assinaturas poéticas da escritora baiana Luciany Aparecida. Dita encarna a função-autor (Foucault, 2002) uma vez que Aparecida desaparece no texto ou perde suas características individuais, fazendo com que o leitor acesse uma projeção de autoria. O segundo aspecto é o recurso dos parênteses onde a autora inclui novas vozes ao texto, formando uma espécie de coro em modo similar ao praticado no teatro clássico.

\footnotetext{
${ }^{1}$ Refiro-me especialmente aos romances Quarto de Despejo, de Carolina Maria de Jesus, A hora da estrela, de Clarice Lispector, e As Mulheres de Tijucopapo, de Marilene Felino. A despeito da necessidade de referenciá-las, acredito ser significativo indicar os anos das obras, 1960, 1977 e 1982, respectivamente.
} 
Obras como as produzidas por Luciany Aparecida ocupam o espaço das formas que mesclam gêneros, vozes e registros inclassificáveis, como pontua Flora Sussekind em Objetos verbais não identificados. Neste ensaio, a crítica já alertava para um cenário contemporâneo posteriormente ampliado, onde as poéticas tradicionais, em formas homogêneas e estáveis, aquelas que ganham mais facilmente o interesse do mercado, dividem espaço com formas de um segundo tipo, essas que ela afirma oportunamente "conectam-se a uma linhagem instabilizadora da literatura brasileira" (Sussekind, 2013, s/n), e acrescento, próximo ao que Florencia Garramuño (2014) virá chamar de "frutos estranhos".

Neste artigo, analiso dois procedimentos utilizados por Luciany Aparecida na composição da novela Florim: em primeiro plano, o emprego da multiplicidade de formas, evocando uma expansão dos gêneros e o questionamento sobre o objeto literário. A seguir, o uso da assinatura em comum acordo com a revelação de sua função-autor (Foucault, 2002), ofertando ao leitor, no pacto de leitura, a ciência de estar diante de um procedimento literário, e capturando-o como agente construtor da obra. A partir de tais empreendimentos, Luciany Aparecida acaba por tensionar o interior da forma, sinalizando para novas composições estéticas no contemporâneo e imaginários também, nos termos encorajados no argumento de Garramuño (2014).

\section{Isso não é uma novela: a inespecificidade da forma}

Qualquer um de nós, estudioso ou leitor comum, depois de dominar a leitura, passou a automatizar o gesto de encontro com o livro como se as formas de ler fossem desde sempre as mesmas e como se os textos ou o que consideramos textos, pelo menos desde a criação do alfabeto grego, fossem impermeáveis ao tempo. E mesmo com o advento de tecnologias que aumentam em velocidade supersônica, pouco paramos para pensar sobre as metamorfoses que certos textos esperam dos leitores. Daí o estranhamento quando algumas obras literárias não cumprem a forma reconhecida pela recepção; um romance que lembra um almanaque, um poema com ares de conto, uma novela que se assemelha a uma peça de teatro, um conto que faz a junção de anotações breves. Desvendar o potencial crítico de textos desses tipos e ouvir os recados que nos mandam a respeito do nosso papel de leitores são duas condições postas para a crítica recente, indisciplinada tal e qual os objetos literários do presente.

Cabe lembrar que a teoria da literatura, em seu movimento nunca linear, poderia ser contada se não pelas famigeradas mudanças de foco de interesse (na obra, no autor e no leitor), por diferentes momentos em que o estatuto do que é literário era defendido, tendo o gênero como um valor indicativo desse esforço e, em vertente oposta, as tensões sobre a regulação desse tipo de arte sugerem ao entender que o literário não precisa estar radicado apenas às construções textuais ou perpetuado nos gêneros finisseculares, podendo compor um terreno ainda inominável. No contemporâneo, na acepção que Giorgio Agamben (2009) nos apresenta, são frequentes novos modos de narrar contaminados pela ideia subliminar de uma literatura pós-autônoma (Ludmer, 2010). Neste bojo, estão obras que se apresentam como experimentos estéticos e que não podemos associar apenas às tecnologias ligadas à rede mundial de computadores, mas também àquelas que dispomos há muito mais tempo e que se tornaram rotineiras para nós, como a fotografia e o cinema. Estas obras partem muitas vezes da tradição, reconfigurando-a, dando-lhe uma nova roupagem, e elas mesmas, ao final do processo, tornando-se inclassificáveis.

Embora a ideia de expansão, sugerida nas reflexões de Rosalind Krauss (1983) a partir da crítica da escultura contemporânea ${ }^{2}$, pareça superada no campo das artes, essa discussão ainda é imprescindível para os estudos literários e potencializada quando os métodos e as técnicas criadas sobretudo a partir dos anos 1990 apontam para o descarte proposital de noções como originalidade e criação (Bourriaud, 2009). A estas podemos somar a ideia de autor e assinatura, conforme antecipado na introdução deste artigo. Portanto, pensar a expansão dos gêneros como

\footnotetext{
${ }^{2}$ Neste texto, originalmente de 1979, Sculpture in the Expanded Field, Rosalind Krauss propõe que diante da perda da especificidade do meio, o que sustentaria o potencial político da arte, é preciso reafirmar a especificidade da arte "como único modo como o discurso artístico poderia ser autocrítico e testar-se em função das suas convenções específicas (Garramuño, 2014, p. 25).
} 
faz Florencia Garramuño e Ana Kiffer (2014), e outros nomes da crítica atual, é também assumir colocar em rota de colisão conceitos muitos caros à teoria da literatura e à crítica literária. É partir do princípio que a indisciplinaridade ou inespecificidade das formas praticada por escritores e escritoras contemporâneos nos coloca o desafio de criar outros parâmetros de análise. É o que nos oferece a leitura da obra de Luciany Aparecida por meio de suas assinaturas poéticas e do transbordamento da novela para fora de si.

Organizado a partir de três tipos de textos e de dicções (um narrador onisciente, o diário de Dita e a poesia de Dita), Florim conta ainda com um quarto elemento que de tão específico, merece ser explicitado à parte. Refiro-me aos coros que acompanham a narrativa entre parênteses e que criam uma possibilidade corpórea de proximidade com o leitor e também de questionamento do próprio fazer literário. As vozes diversas que compõem esse elemento do texto lembram em certa medida o que faz Sérgio Sant'Anna em Um discurso sobre o método (1989), ali também problematizando a representação do pobre e as distâncias ao abordar esteticamente nossos problemas sociais. Nos dois casos, apreende-se se tratarem de "personagens" que passam rapidamente pelo texto, como coadjuvantes e cuja força está exatamente na soma de todos, vistos como um conjunto.

Essa soma de vozes amplificada nos parênteses poderia ser enunciada pelos leitores ou por qualquer pessoa que observa a história e opina a respeito dela de longe, como uma conversa, um burburinho. Em se tratando de literatura, essa percepção "extra", um braço dado ao leitor, aparece também por meio da epígrafe da obra, o texto de Lima Barreto, Casa de poetas (comédia em um ato) (2018), em que o autor também recorre aos parênteses para criar uma nova possibilidade de manobra do texto para o leitor: "CLARIMUNDO (paternalmente)", "CLARINDA, (voltandose)", "LUís (obediente e saindo)" são alguns exemplos das marcações dadas pelo autor. Elas são movimento na cena, bem como dão a ver o estado de espírito dos personagens, como cada qual se sente durante esse diálogo. Nos três casos aqui elencados, vozes externam corroboram para certa modulação no texto, por consequência para o ato de leitura e põe fim para qualquer certeza empreendida por seus narradores.

Na novela Florim, a tradição remonta às técnicas utilizadas pelo teatro clássico, em que temos como exemplos Édipo em Colono e Édipo Tirano, de Sófocles ${ }^{3}$, e desliza para o texto atual como intervenções às falas da narradora e de Dita. Esta manobra textual aciona um outro elemento de força ao texto, o encontro entre dois gêneros (novela e teatro) ou a fissura da "novela", como podemos observar no trecho a seguir, na passagem em que o assassinato de Dita é narrado:

Pisaram na mãe que contava menino até aniquilar o cheiro. Deixaram a morrinha de sangue pocado. Foi pelo amontoamento daquele papel nauseado que a reconheceram.

- É Mainha! (Desonra).

- É a vizinha! (Coragem de +1).

- É negra (Seção policial).

- É a que escreve! (Contagem de +1 +lamento +desonra).

- É marginal! (Boca da TV).

- É o amante! (Boca de TV).

- Filho demais também! Por que não pariu menos? Ah, mas não podia, tinha de receber a blá-blá-blá. (Comentarista da Boca da TV) (Ducaso, 2020, p. 52-53).

O modo como se dá o retorno do coro em Florim destoa do que é praticado na produção literária atual, sem deixar de se alinhar, no entanto, às exceções ou formas inaugurais de Eles eram muitos cavalos (2001), de Luiz Ruffato, com sua multiplicidade vocal, ou a coralidade realçada em Delírio de Damasco (2012), de Verônica Sttiger. Vejamos que aqui temos supostamente três gêneros, novela, romance e poema, em que o que menos importa no ato de leitura é exatamente a classificação do texto, afinal são composições literárias incomodadas com as bordas convencionais. A fatura de exercícios textuais como esses, no entanto, já convive com o contemporâneo por outros caminhos artísticos há mais tempo. Flora Sussekind (2013) recupera o trabalho de José Celso Martinez Corrêa e o Teatro Oficina Uzina Uzona ao citar o teatro e a

\footnotetext{
${ }^{3}$ Sófocles (496-406-5 a) escreveu mais de cem peças, mas acredita-se que apenas sete destas chegaram completas à atualidade. São elas: Antígona, Édipo Tirano, Electra, Ajax, As Traquínias, Filoctetes e Édipo em Colono e o drama satírico Perseguindo Sátiros.
} 
reinvenção de coros-protagonistas do teatro clássico. A partir da reflexão da crítica, posso acrescentar ainda que Florim ecoa vozes diversas como se fosse uma caixa acústica, abrigando a coralidade em que cabe de tudo um pouco: (seção policial), (mentira), (coro), (seção perigo), (boca do povo), (classificados), (stand up), entre outras claques indicadas no livro de Ducaso.

O próprio termo coro é utilizado na narrativa durante o encontro dos filhos com o corpo de Dita, nesse momento escancarando a mobilidade do gênero textual para além da moldura:

Ney, o único menino de fala, e os menino, passavam a mão na massa recordando molde de gente.

- Chora de saudade rua inteira. Deixa a lembrança do corpo-de-nesse-instante passear. (Coro Baixo).

- Alisa qualquer parte tristeza, busca o que é teu que aqui jaz nesse corpo disforme. (Coro Baixo) (Ducaso, 2020, p. 51).

A inespecificidade apontada pelo livro dialoga com outros sistemas de arte, mas apesar de não recorrer a outros materiais como aportes de produção (a exemplo de obras que de fato utilizam frames de cinema, fotografia, publicidade etc.), encaixa-se ao que a crítica argentina Florencia Garramuño abordará em Formas da impertinência (2014). Neste artigo, em que a crítica explora a perturbação provocada pela obra Fruto Estranho (2010), de Nuno Ramos, ela desenvolve a ideia de que:

a noção de forma do não pertencimento - e até da não pertinência - quer apontar mais para um modo ou dispositivo que evidencia uma condição da estética contemporânea na qual forma e especificidade parecem ser conceitos que não permitem dar conta daquilo que nela está acontecendo" (Garramuño, 2014, p. 92).

Cabe lembrar, a título de contraponto e também de exemplo possível para o argumento da crítica, o grande sucesso editorial, o romance Torto Arado (2019), do também baiano Itamar Vieira Jr. Em termos formais, podemos dizer que o romance que virou um fenômeno como há muito anos não se via, refaz o elogio ao maior dos gêneros em nosso mercado editorial, o romance. A aproximação entre o romance das irmãs Belonísia e Bibiana e a novela de Dita soa pertinente, porque além de conterrâneos, os dois escritores se interessam por temas comuns, a questão do racismo, a violência que opera a partir dessa tecnologia de poder, tendo por contexto uma Bahia não anunciada explicitamente, em Florim, o urbano, e em Torto Arado, o rural. Ainda assim são dois livros que, independentemente dos seus gêneros, dão soluções diferentes no que se refere à forma, o primeiro em uma perspectiva desestabilizadora do gênero e o segundo mantendo um formato estabelecido. ${ }^{4}$

Munida apenas de palavra, Luciany Aparecida maneja o texto como quem credita ao leitor a missão de emprestar seu corpo para o encontro com a narrativa. As mudanças de dicção entre os tipos de narradora, bem como os parênteses que acompanham praticamente todo o processo narrativo podem perfeitamente abrir mão da leitura silenciosa, ou da leitura individual, como se o coro convocasse a recepção para a leitura em voz alta, como se o coro quisesse ser enfim o que a autora empírica do texto assim desejou.

É interessante também notar que as marcações a que nos referimos não dizem respeito apenas a grupos de sujeitos ou reações específicas, podendo também trazer outras referências como na largada da novela quando Dita escreve: "Cheguei da Feira-livre. Guardei o que trouxe da rua na geladeira. O que não coube tento conservar neste diário. Sou experimento do ódio. Peça de mercado. (Sopro de vento colonial)" (Ducaso, 2020, p. 13). O convite à recepção mantém-se como marca dos outros livros de Aparecida. Dita ou Ruth, ou quem quer que seja a voz a nos guiar nessa leitura, anuncia o mistério da protagonista, cuja história é costurada com dados do período colonial, com o mito da orixá Iansã nas religiões de matriz africana, porém à luz dos dias de hoje. Se o tempo também pode ser atrelado ao gênero em que se escreve, a narrativa de Florim suspende-o, ou melhor, dilata-o, abrindo uma brecha em que passado e futuro são conciliados, pouco importando se o narrado parece verossímil. A relação entre realidade e temporalidade se

\footnotetext{
${ }^{4}$ Esclareço que a comparação entre as narrativas não diz respeito a qualquer critério de ajuizamento das obras. A aproximação diz respeito ao tratamento formal dos gêneros escolhidos (romance e novela), com vistas a uma possível recepção da obra por ser mais ou menos próximo ao que o grande público espera ou está habituado a consumir.
} 
dá por outra ordem e assim um segundo sentido para a palavra florim viaja no tempo e se empresta a outros caminhos interpretativos. Além do primeiro sentido, associado à orixá Iansã, como lembra Denise Carrascosa no posfácio:

Do vendedor, sabemos também que florim, medida de moeda europeia medieval, era feita cidade vizinha de algumas famosas tragédias da ilha imperial. Tinha, como toda moeda, no verso do valor monetário, a coroa - um símbolo do poder familiar hereditário e citadino um lírio: flor de pureza e paixão, paz e sangue, do branco e do vermelho amiga, movente da criação e do caos (2020, p. 66).

Seja no indício anunciado entre parênteses, seja nos diversos significados na palavra florim, a novela propõe ao leitor que esta história não começa na Cidade Sanha, nem em Salvador, muito menos no Brasil de agora. Nesse sentido, a técnica utilizada por Aparecida também promove um segundo movimento anunciado por Garramuño (2014), ao afirmar que as formas expandidas promovem não apenas um questionamento da forma, mas também lançam a proposição de novos imaginários ou novos imaginários para as comunidades. Assim, o passo sutil que Florim dá do presente ao passado, retornando ao presente mais uma vez, convida os leitores a um deslocamento de tempo, mas de experiências diferentes daquelas a que estão habituados, ou o “imaginar-se no lugar de".

\section{Um nome para uma invenção: Ruth Ducaso}

Qualquer questionamento da autoria deve partir da noção de autoria em si mesma. Ou seja, para pensarmos a assinatura Ruth Ducaso como uma provocação de autoria, é preciso um recuo a respeito dos modos de entendimento do autor, desde as duas reflexões fundamentais sobre o assunto desenvolvidas por Roland Barthes (2004) e Michel Foucault (2002) ${ }^{5}$. Em um segundo passo, sim, os desdobramentos desse conceito no contemporâneo, entendendo que a substituição de uma presença de autor com autoridade sobre um discurso por uma assinatura, revela além da função-autor, um procedimento estético sublinhado na obra.

Florim é definido em sua ficha catalográfica como novela, o segundo dos livros do projeto literário de Luciany Aparecida e, embora se interligue aos demais escritos da autora, pode ser lido como uma obra independente. Chama atenção na produção da autora o relevo que a questão da assinatura poética ganha, uma vez que Aparecida não esconde o próprio nome, este dividindo espaço com a assinatura da vez (literalmente espaço, na materialidade do objeto livro, na orelha, na quarta capa etc.).

Em entrevistas, lives e palestras, Luciany Aparecida costuma explicar o que, no seu entendimento, marca a diferença entre heterônimos e assinatura poética, em uma defesa do tipo de procedimento a que se dedica. A impressão que se tem é de que, para a autora, a assinatura poética pode ser compreendida como certa dicção operada no interior das construções textuais e de acordo com a autoria que a escritora pretende desenvolver naquele momento. Não se trata, portanto, apenas de um regime de propriedade das obras, o que alude ao princípio da autoria quando o autor poderia inclusive ser aquele que reunia textos de terceiros, sem correr o risco de o acusarem de plagiador.

Em seu primeiro livro, Luciany Aparecida apresenta seu projeto literário, a criação de um conjunto de textos a partir da experiência de escrita narrativa (conto, carta, novela e romance), resultado também de um prêmio de criação da Biblioteca Nacional/Funarte. $\mathrm{O}$ uso de diferentes assinaturas diz respeito, portanto, ao tom do texto, à forma, assim como ao gênero explorado no empreendimento escolhido. A partir disso, Luciany Aparecida assina como Ruth Ducaso nos livros já citados, em outros momentos como Margô Paraíso, autora de Ezequiel (2018) e considerada uma escritora morta, e Antônio Peixôtro, que faz dupla com Ruth Ducaso em Auto-retrato (2018). Quanto ao leitor, este tem acesso a essa mistura de assinaturas e nome da escritora sem subterfúgios. Na

\footnotetext{
${ }^{5}$ As obras citadas são de 1968 e 1969 , no entanto neste texto indico as datas das edições consultadas de $A$ morte do autor e $O$ que é um autor? respectivamente.
} 
orelha de Florim, por exemplo, consta uma fotografia de Luciany Aparecida juntamente com seus dados biográficos, permitindo fazermos certa distinção diante da assinatura de capa.

Se o nome Ruth Ducaso é associado a um tipo de texto, o mesmo não se pode dizer de Luciany Aparecida. Sua presença em Florim e em outros textos é na condição de autor-curador, ainda assim, como já dito, restrita a alguns espaços do livro. Não há um texto específico com a sua assinatura. Mais recentemente, a escritora escreve Joanna Mina, dramaturgia selecionada pelo edital Peças em processo do Teatro da Universidade de São Paulo (USP). Em entrevista, ela afirmou estar à procura "de um lugar para a assinatura Luciany Aparecida". ${ }^{6}$ Joanna Mina poderá ser este lugar, o que garante, no meu entendimento, uma nova assinatura, mas não uma presença subjetiva, porque como defende Foucault no clássico texto O que é um autor?: "na escrita, não se trata da manifestação ou da exaltação do gesto de escrever; não se trata da amarração de um sujeito em uma linguagem; trata-se da abertura de um espaço onde o sujeito que escreve não para de desaparecer" (2002, p. 44). Roland Barthes se aproxima desse entendimento desde o começo de A morte do autor. Logo nas primeiras linhas, ele diz: "A escritura é esse neutro, esse composto, esse oblíquo pelo qual foge o nosso sujeito, o branco-e-preto em que vem se perder toda identidade, a começar pelo corpo que escreve" (Barthes, 2004, p. 57). Ele também frisa o percurso de surgimento da noção de autor, não tão longevo:

uma personagem moderna, produzida sem dúvida por nossa sociedade na medida em que, ao sair da Idade Média, com o empirismo inglês, o racionalismo francês e a fé pessoal da Reforma, ela descobriu o prestígio do indivíduo ou, como se diz mas nobremente, da pessoa humana (2004, p. 58).

A questão que se interpõe no caso de Florim é a escolha pela substituição de nome e a associação que uma assinatura faz com um certo tipo de modulação textual. Florim não é o primeiro livro de Ruth Ducaso. Antes, ela também assinou Contos ordinários de melancolia (2019). A assinatura confronta a definição de objeto literário, afinal há muito que a autoria se associa ao documento literário como vimos com Barthes e Foucault. Esse último nos lembra ainda que todo texto é em certo grau uma artimanha, fator que não pode ser desmerecido, e como tal tem seu modo de operar. Segundo ele:

Pode-se dizer, inicialmente, que a escrita de hoje se libertou do tema da expressão: ela se basta a si mesma, e, por conseqüência, não está obrigada à forma da interioridade; ela se identifica com sua própria exterioridade desdobrada. O que quer dizer que ela é um jogo de signos comandado menos por seu conteúdo significado do que pela própria natureza do significante; e também que essa regularidade da escrita é sempre experimentada no sentido de seus limites; ela está sempre em vias de transgredir e de inverter a regularidade que ela aceita e com a qual se movimenta; a escrita se desenrola como um jogo que vai infalivelmente além de suas regras, e passa assim para fora (Foucault, 2002, p. 44).

Em outro registro teórico, também é possível ler a estratégia utilizada por Luciany Aparecida como um trabalho de construção do "design de si", termo utilizado por Boris Groys (2016) e que trata de processos artísticos em que a realidade dada ao público não estabelece relação imediata com a referencialidade. Como tenho dito em outros textos, escritores contemporâneos que lançam mão dessa manobra criam um artista como parte da composição da obra. No caso de Ruth Ducaso, portanto, não estamos diante apenas de um nome ou uma assinatura poética, mas de uma performance específica que reflete e refrata um discurso de autoria.

\section{Considerações finais}

Florim, assinado por Ruth Ducaso e escrito pela autora baiana Luciany Aparecida, é desses exemplares contemporâneos que põem diante de nós a uma só vez alguns dos mais caros problemas da teoria e da crítica literária. Autoria, assinatura, gênero, inespecificidade são alguns

\footnotetext{
${ }^{6}$ A entrevista com a autora foi realizada, por email, em 23 abril de 2021, como parte da investigação em andamento no pós-doutorado por mim realizado. Antes disso, em janeiro de 2019, fiz uma primeira entrevista presencial com a autora a propósito da publicação de Ezequiel (2018). Por fim, em agosto de 2021, publiquei uma resenha sobre Florim no Suplemento Pernambuco.
} 
dos temas evocados na narrativa, apresentada como novela, mas que, desde a epígrafe de Lima Barreto, dá sinais de que será um livro em expansão.

As principais questões realçadas na narrativa, o hibridismo de gêneros textuais e a opção de um "nome falso", na verdade uma performance da autoria na máquina do texto, questionam o literário e algumas das suas categorias clássicas, apresentando-se como desafios para a crítica. E também para a recepção, que precisa se desvencilhar de um protocolo já datado de leitura. A pista quem dá é a narradora de Dita: “Um dia, decidi escrever. Ela, eu e os espasmos de nossos silêncios. Esse é um caminho de farta sinalização. As cavidades não são erros. Tua desconfiança é tempo. Deixa quedar teu tino. Leitura é coragem e permissão (Ducaso, 2020, p. 11).

As manobras de Luciany Aparecida podem ser identificadas como pertencentes aos tipos de texto de segunda ordem de que fala Flora Sussekind em Objetos verbais não identificados ou às práticas da impertinência, nos termos de Florencia Garramuño. Em comum, as duas críticas observam uma produção contemporânea apartada de certos textos já estabelecidos tanto no campo literário quanto pelo mercado editorial. São textos que subvertem a forma, implodem os gêneros por dentro e oferecem por um lado as metamorfoses da forma literária, e de outra permitem a suposição de imaginários diferenciados. Ruth Ducaso nasceu para que sujeitos como Dita tivessem enredo próprio, poemas próprios como esse trecho em que diz:

Do meio da ponte,

Fotografar a linha final da vida,

Guardar a fotografia no bolso, forrada com um pedaço de plástico roubado de algum álbum de família

Sangrar o rio (Ducaso, 2020, p. 46).

Por fim, ao criar Ruth Ducaso, como um artifício performático por meio do qual um tipo de dicção literário é veiculado, Luciany Aparecida ao primeiro passo promove uma inflexão na noção de autoria. O segundo passo é a criação de uma "novela-teatro", a partir do recurso do coro. O terceiro e último movimento é o próprio enredo, ao forjar uma personagem mulher, negra, periférica e escritora, aludindo ao passado colonial, à influência da religiosidade de matriz africana, todos esses elementos dando musculatura a uma narrativa que nos permita vislumbrar sujeitos negros a partir de outro lugar.

\section{Referências}

AGAMBEN, Giorgio (2013). O que é o contemporâneo? e outros ensaios. Tradução de Vinícius Nicastro Honesko. Chapecó: Argos.

BARRETO, Lima (2018). Casa dos Poetas. In: BARRETO, Lima. Histórias e sonhos (1920). São Paulo: WMF Martins Fontes. E-book.

BARTHES, Roland (2004). A morte do autor. In: BARTHES, Roland. O rumor da língua. Tradução de Mário Laranjeira. São Paulo: Martins Fontes (Coleção Roland Barthes).

BOURRIAUD, Nicolas (2009). Pós-produção: como a arte reprograma o mundo contemporâneo. São Paulo: Martins Fontes.

CARRASCOSA, Denise (2020). Posfácio. In: DUCASO, Ruth [Luciany Aparecida]. Florim. Salvador: paraLeLo $13 S$.

DERRIDA, Jacques (1991). Assinatura Acontecimento Contexto. In DERRIDA, Jacques. Margens da Filosofia. Tradução de Joaquim Costa e António Magalhães. Campinas: Papirus. p. 349-373.

DUCASO, Ruth [Luciany Aparecida] (2019). Contos ordinários de melancolia. Salvador: paraLeLo $13 S$.

DUCASO, Ruth [Luciany Aparecida] (2020). Florim. Salvador: paraLeLo $13 S$.

DUCASO, Ruth; PEIXÔTRO, Antônio [Luciany Aparecida] (2018). Auto-retrato. Salvador: Editora Pantim. FOUCAULT, Michel (2002). O que é um autor? Tradução de António Fernando Cascais. Lisboa: Vega. 
GARRAMUÑO, Florencia (2014). Frutos estranhos: sobre a inespecificidade na estética contemporânea. Tradução de Paloma Vidal. Rio de Janeiro: Rocco.

GÓIS, Edma de (2021). Uma caixa acústica com muitas vozes. Suplemento Pernambuco, Recife, n. 186, p. 28, ago.

GROYS, Boris (2016). La obligación del diseño de si. Traducción del Paola Cortes Rocca. In: GROYS, Boris. Volverse público: las transformaciones del arte en el ágora contemporânea. Buenos Aires: Caja Negra. p. 21-36.

KIFFER, Ana; GARRAMUÑO, Florencia (2014). Expansões contemporâneas: literatura e outras formas. Belo Horizonte: Editora UFMG.

KRAUSS, Rosalind (1983). Sculpture in the expanded field. In: FOSTER, Hal (ed.). The anti-aesthetic: essays on postmodern culture. Washington: Bay Press. p. 31-42.

LUDMER, Josefina (2010). Literaturas pós-autônomas. Sopro 20, Desterro.

PARAÍSO, Margô [Luciany Aparecida] (2018). Ezequiel. Salvador: Editora Pantim.

SANT'ANNA, Sérgio (1989). Um discurso sobre o método. In: SANT'ANNA, Sérgio. A senhorita Simpson: histórias. São Paulo: Companhia das Letras. p. 87-106.

SUSSEKIND, Flora (2013). Objetos verbais não identificados. O Globo, Rio de Janeiro, 21 set. Disponível em: https://blogs.oglobo.globo.com/prosa/post/objetos-verbais-nao-identificados-um-ensaio-de-florasussekind-510390.html Acesso em: 27 ago. 2021

VIEIRA JUNIOR. Itamar (2019). Torto Arado. São Paulo: Todavia.

\section{Nota}

Este artigo integra pesquisa em andamento, financiada pela Coordenação de Aperfeiçoamento de Pessoal de Nível Superior (Capes), por meio do Programa Nacional de Pós-Doutorado (PNPD). 